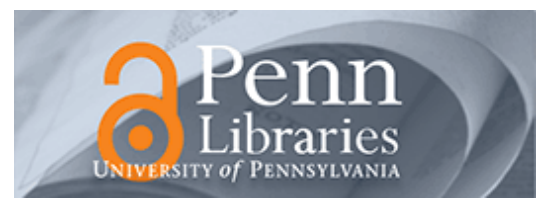

University of Pennsylvania

ScholarlyCommons

Management Papers

Wharton Faculty Research

$2-2003$

\title{
Startup Size and the Mechanisms of External Learning: Increasing Opportunity and Decreasing Ability?
}

\author{
Paul Almeida \\ Gina Dokko \\ Lori Rosenkopf \\ University of Pennsylvania
}

Follow this and additional works at: https://repository.upenn.edu/mgmt_papers

Part of the Business Administration, Management, and Operations Commons

\section{Recommended Citation}

Almeida, P., Dokko, G., \& Rosenkopf, L. (2003). Startup Size and the Mechanisms of External Learning: Increasing Opportunity and Decreasing Ability?. Research Policy, 32 (2), 301-315. http://dx.doi.org/ 10.1016/S0048-7333(02)00101-4

This paper is posted at ScholarlyCommons. https://repository.upenn.edu/mgmt_papers/156

For more information, please contact repository@pobox.upenn.edu. 


\title{
Startup Size and the Mechanisms of External Learning: Increasing Opportunity and Decreasing Ability?
}

\author{
Abstract \\ An important area of investigation in the field of entrepreneurship examines how people and \\ organizations exploit technological opportunities. Prior research suggests that alliances, the mobility of \\ experts, and the informal mechanisms associated with geographic co-location can present firms with \\ useful opportunities to source technological knowledge. This paper uses insights from strategic \\ management and organizational theory to suggest that organizational size may have an important impact \\ on the extent of external learning, since it differentially affects the likelihood of learning via formal and \\ informal mechanisms. \\ Examining a cross-section of semiconductor startups, we find that external learning increases with \\ startup size. With regard to the specific mechanisms of learning, we find that firms learn from alliances \\ regardless of their size. For the informal mechanisms of mobility and geographic co-location, however, \\ learning decreases with firm size. These results suggest that as startups grow, they may have increasing \\ opportunities to access and exploit external knowledge, but their motivation (and hence ability) to learn \\ from more informal sources may decrease.

\section{Keywords} \\ external learning, firm size, entrepreneurship \\ Disciplines \\ Business Administration, Management, and Operations
}




\title{
Startup Size and the Mechanisms of External Learning: Increasing Opportunity but Declining Usefulness?
}

\author{
Paul Almeida \\ McDonough School of Business \\ Georgetown University \\ Washington, DC \\ (202) 687-3822 \\ almeidap@georgetown.edu \\ Gina Dokko \\ Department of Management \\ The Wharton School \\ University of Pennsylvania \\ Philadelphia, PA 19104-6370 \\ (215) 898-7819 \\ dokko@management.wharton.upenn.edu \\ Lori Rosenkopf \\ Department of Management \\ The Wharton School \\ University of Pennsylvania \\ Philadelphia, PA 19104-6370 \\ (215) 898-6723 \\ rosenkopf@wharton.upenn.edu
}

February 23, 2001

The authors are listed alphabetically. We appreciate the suggestions of Rob Grant, Elaine Romanelli and the participants of the Technology Entrepreneurship Research Policy Conference at the R.H. Smith School of Business, University of Maryland. We also thank two anonymous reviewers for their valuable comments. Financial support for this project was provided by the Huntsman Center for Global Competition and Innovation at the Wharton School, University of Pennsylvania. Samson Lo, Eileen McCarthy, Anjana Pandey, Narayan Raj, and Preetam Rao all contributed valuable research assistance. 


\title{
Startup Size and the Mechanisms of External Learning: Increasing Opportunity but Declining Usefulness?
}

\begin{abstract}
An important area of investigation in the field of entrepreneurship centers on how people and organizations exploit technological opportunities. Prior research suggests that alliances, the mobility of experts, and the informal mechanisms associated with geographic co-location can present firms with useful opportunities to source technological knowledge. This paper uses insights from strategic management and organizational theory to suggest that organizational size may have an important impact on the extent of external learning, since it differentially affects the likelihood of learning via these mechanisms.

Examining a cross-section of semiconductor startups, we find that external learning increases with startup size. With regard to the specific mechanisms of learning, we find that firms learn from alliances regardless of their size. For the informal mechanisms of mobility and geographic co-location, however, learning decreases with firm size. These results suggest that as startups grow, they may increasingly access and exploit external knowledge, but their motivation to learn from more informal sources may decrease.
\end{abstract}




\section{Introduction}

The field of entrepreneurship has been defined as "...the study of sources of opportunities, the processes of discovery, evaluation, and exploitation of opportunities; and the set of individuals who discover, evaluate and exploit them" (Shane and Venkataraman 2000:218). The opportunities that are presented to firms are often technological in nature and the ability to respond to these opportunities (or technological entrepreneurship) is increasingly tied to a firm's success. Research on organizational learning suggests that one source of technological opportunity available to firms is the exploitation of external knowledge for innovation (e.g. Cohen and Levinthal 1990). Prior research also suggests that a variety of mechanisms may be used to access this knowledge. These mechanisms include the hiring of scientists and engineers (Zucker 1998; Almeida and Kogut 1999), the forming of strategic alliances (Mowery, Oxley et al. 1996; Rosenkopf, Metiu et al. 2000) and the appropriation of informal networks (Liebeskind, Oliver et al. 1996; Almeida and Kogut 1997; Rosenkopf and Tushman 1998). Though our understanding of the mechanisms of external knowledge sourcing has grown in recent years, a critical question is still left on the table: What firm characteristics facilitate the exploitation of knowledge accessible via these mechanisms?

In this paper, we seek to shed light on one aspect of this question. Specifically, we study the relationship between startup size and the use of three mechanisms of external knowledge acquisition - expert mobility, alliances and informal geographically mediated networks. The focus on size is interesting, since on one hand, studies suggest that scale economies and superior organizational resources permit larger firms to successfully access and exploit knowledge from the environment (Kogut and Zander 
1993). On the other hand, learning studies in organization theory suggest that a firm's motivation to source external knowledge may decrease with size - firms may grow increasingly inward looking and ignore external knowledge (Levinthal and March 1993). We argue here that with increased size, startups may be able to source and use more knowledge from external sources because of the greater scale and scope of their activities: they have more ties to the outside world and greater ability to exploit knowledge internally. However, with an increase in size, this study suggests that startups do not always increase their utilization of a given knowledge mechanism. We hypothesize that while larger firms may learn more from formal mechanisms such as alliances, they may in fact learn less from more informal mechanisms, such as mobility. Venkataraman (1997:121) suggests that one of the key questions facing the field of entrepreneurship is “...why, when and how some are able to discover and exploit opportunities while others cannot or do not." Our study highlights the role of size in explaining which startups are best able to access and exploit the exploit knowledge opportunities via organization-level and individual-level mechanisms. Our emphasis on startups is important since new firms, particularly those in the semiconductor industry, are especially reliant on innovation to compete with more established firms. Furthermore, startups play an important role in the exploration of new technological areas and rely on other firms for much of their technological knowledge (Almeida and Kogut 1997). Thus we hope to contribute to the field of technological entrepreneurship by shedding some light on when and how startups can exploit the opportunities presented by the mechanisms of external learning. 
In this study, we examine the patent citation patterns of semiconductor startups. Recent scholarship in technology entrepreneurship has highlighted the value of patent data in analyzing the dynamics of innovation (Stuart 1998; Ahuja and Lampert 2000). The results of our study indicate that larger startups learn more from others in the industry than smaller ones. Yet while larger startups learn more, we find that increasing size is associated with a decrease in the usefulness of mobility and geographic colocation for external learning. Our paper proceeds as follows. In Section 2 we develop the theory and hypotheses regarding the relationship between firm size and the likelihood of learning from alliancing, mobility, and geographically mediated informal networks. Section 3 discusses the use of patent data and describes our methodology. Section 4 presents our findings and Section 5 discusses the results and extensions of this study.

\section{Theory and Hypotheses}

\subsection{The Mechanisms of External Learning}

Though most firms internally develop much of the knowledge used in innovation, few firms possess all the inputs required for successful and continuous technological development. Organizations often turn to external sources to fulfill their knowledge requirements (Rosenkopf and Nerkar forthcoming). In fact, suppliers, buyers, universities, consultants, government agencies and competitors all serve as sources of vital knowledge (Jewkes, Sawers et al. 1958).

How does a firm exploit external knowledge? Cohen and Levinthal (1990) pointed to the absorptive capacity of a firm that permits it to recognize, absorb and utilize outside sources of knowledge. But recognizing the importance of outside knowledge, 
which arises from investments in $\mathrm{R} \& \mathrm{D}$, does not necessarily permit a firm to access and assimilate it. Nor does it explain why firms are attentive to knowledge from certain sources and less attentive to others. Firms need to develop conduits or mechanisms that permit the absorption and use of external knowledge. It is these conduits that also channel the externally available knowledge, and determine which knowledge the firm actually uses for invention.

Hayek (1945) suggested that opportunity discovery is a function of the distribution of knowledge among actors in a market. Analogously, we suggest that the ability to exploit knowledge generated by others is a function of the firm's access to this knowledge. Formation of alliances, hiring of inventors from competitors, and informal social networks within geographic regions all generate idiosyncratic differences in knowledge access. Indeed, Almeida and Rosenkopf (1997) used patent citation data to evaluate the three mechanisms of learning, and found that all three mechanisms play a role in facilitating external learning by semiconductor startups.

\subsubsection{Alliances and Learning. Since Hamel, Doz and Prahalad (1989) first} suggested that alliances should be viewed as learning opportunities, several studies have supported this idea (e.g., Gulati 1995; Eisenhardt and Schoonhoven 1996). For instance, Powell, Koput, and Smith-Doerr (1996) postulate the existence of "networks of learning", and suggest that participation in networks of R\&D alliances facilitates the growth of new biotechnology firms. In-depth case studies also provide us with a rich illustration of learning between alliance or network partners (e.g., Inkpen and Crossan 1995; Doz 1996). Recent studies on alliances have used patent citation data to track knowledge flows across organizations and regions more directly and have suggested that alliances 
can lead to inter-firm learning (Mowery, Oxley et al. 1996; Stuart and Podolny 1996).

2.1.2 Mobility and Learning. The notion that the mobility of people facilitates the flow of knowledge is hardly new. There are numerous studies relating the two, though most provide only indirect support for the idea that inter-firm mobility leads to inter-firm learning (e.g., Bell 1984; Markusen, Hall et al. 1986; Malecki 1991; Boeker 1997). As was the case for alliance research, the most accessible direct evidence linking mobility of engineers to interfirm knowledge building may be accomplished through patent records. Almeida and Kogut (1999) tracked over 400 engineers in a study of semiconductor firms, and showed that the mobility of engineers between firms in a region led to the localization of knowledge within the region, while the mobility of engineers across regions led to a decrease in regional knowledge.

2.1.3 Geographic Regions and Learning. Research points to the importance of geographically clustered social networks in facilitating the informal diffusion of knowledge across firms (Rogers and Larson 1984). Case studies of regional clusters in Italy (Piore and Sabel 1984) and Baden-Wuerttemberg in Germany (Herrigel 1993) indicate extensive knowledge flows through networks in these regions. Locational proximity reduces the cost and increases the frequency of personal contacts, which serve to build social relations between players in a network (Dorfman 1987; Saxenian 1990; Almeida and Kogut 1997) that can be appropriated for learning purposes.

\subsection{External Learning and Size}

We extend the previous investigations of the role of these three mechanisms for external learning by exploring the relationships between firm size, learning, and the usefulness of the mechanisms. 


\subsubsection{Advantages of Size for Learning. We argue here, that as startup size}

increases, the likelihood that it will access and exploit outside knowledge increases because of its increased number of interfaces to the external environment and its increased opportunity and ability to exploit this knowledge internally.

An increase in size is usually accompanied by an increase in the technological, product market and geographic scope of its activities (Patel and Soete 1987). As startup size increases, they are provided with greater opportunities to learn from external sources. Studies in the area of international strategy point to the relationship between geographic scope and learning - multinational firms are able to access knowledge through location of subsidiaries in knowledge intensive regions (Porter 1990). Through the expansion of the geographic scope of activities, large startups have the opportunity to tap into the expertise of multiple regions (within or across countries) through a variety of formal and informal mechanisms (Bartlett and Ghoshal 1989; Almeida and Kogut 1997). Similarly, technological expertise and increased scope provides firms with greater opportunities to trade and exchange knowledge. Von Hippel (1994) suggests that firms often use the ownership of patents as trading 'chips' in the exchange of knowledge. Firms that do not possess a broad knowledge portfolio may be locked out of this opportunity for knowledge trading. Therefore, we can expect larger startups to have a greater opportunity than smaller ones to access external knowledge.

Given the larger scale and scope of activities of larger startups, they are more likely to be able to not just acquire, but also exploit, externally acquired knowledge in their innovative activities. First, larger firms have greater opportunities to reap scale and scope economies in the exploitation of newly acquired knowledge across businesses, 
locations and products. To fully exploit these opportunities for innovation, startups must depend on their organizational and managerial resources and capabilities. The development of linkages to outside sources of knowledge that act as conduits for knowledge transfer requires a substantial investment of resources (Dyer and Nobeoka 2000). Furthermore, the firms must have the ability to combine existing knowledge with new (externally acquired or internally generated) knowledge for innovation. This managerial ability requires the transfer of knowledge from the points of access - through boundary spanners and gatekeepers (Allen 1983) - to locations within the firm where this knowledge can be usefully exploited. The nature of innovation, as well as the tacit and complex nature of knowledge, may require that several sub-units interact actively across extended periods of time to build new products or processes (Sakakibara and Westney 1992). To facilitate this knowledge building process, startups must establish intraorganizational mechanisms, processes and systems to link various sub-units across time (Almeida, Grant and Song, 1998). Thus, the complex tasks of knowledge recognition, absorption and utilization require the possession of significant managerial and organizational resources and capabilities. Larger startups are more likely to possess these resources and the organization to meet the challenge of external knowledge utilization.

Hypothesis 1: The likelihood of a startup learning from other organizations increases with its size.

2.2.2 External Learning and the Limitations of Size. In spite of its many advantages, size can have drawbacks. Larger firms often rely on experiential learning, which according to Levinthal and March (1993: 97) "has its own traps". The authors suggest that experiential learning encourages the organization to focus on issues and technologies close to its current experience. Knowledge close to existing technological 
and market conditions will be highly valued, while more distant knowledge, for instance knowledge available outside the firm, may lose its salience and significance. Levinthal and March call this failure to access more distant knowledge " the myopia of learning". The myopia suggests that larger firms may grow increasingly inward looking and shortsighted due to positive feedback that experience provides or simply from inertia. This view is corroborated by Sorenson and Stuart (2000), who demonstrate an increasing tendency of technology firms to self-cite (in their patent records) over time.

Another reason that larger firms may have difficulty assimilating external knowledge is their increased used of distinctive shared language and symbols that allow for effective communication within organizations. Cohen and Levinthal (1990) in their discussion of internal structures of communication, refer to this efficiency of communicating internally as an inward-looking absorptive capacity, and suggest that it is offset by a corresponding decrease in the ability to absorb external knowledge. This tradeoff may explain the not-invented-here (NIH) syndrome, in which communication with external groups decreases over time (Katz and Allen 1982).

Finally, large firms may differ from smaller firms in their openness to external knowledge simply because of strategic motivation. March (1991) views knowledge development as going through phases - starting with an exploration phase and later going on to an exploitation stage. Exploration activities are oriented towards the accessing of new ideas, while exploitation relies on relies on the replication of existing competencies under diverse conditions. In their study of the semiconductor industry, Almeida and Kogut (1997) suggest that in many industries, startups receive funding because they explore new technological spaces and opportunities that are ignored by larger firms. A 
range of factors including financing, government regulations, and the motives and goals of the entrepreneurs provide conditions for small firms that are more amenable to the exploration of new technology (Acs and Audretsch 1990). Hence small firms are better equipped to exploit new technological opportunities and hence more attuned to knowledge available outside the firm.

In short, there are opposing arguments regarding the relationship between firm size and the likelihood of acquiring and using knowledge from outside the firm. One argument outlines the advantages of size arising from connections to the outside world, and the greater opportunities and resources to exploit this knowledge internally. The countervailing argument concerns the decreasing motivation and increasing myopia of larger firms when considering use of external knowledge. We propose that the relative strength of these two views, and the corresponding growth or decline in knowledge utilization, depends on the type of learning mechanisms being employed by the startup. 2.3 Interactions of Mechanisms and Size

\subsubsection{Firm Size and Alliances. Alliances are formed for a number of reasons} including strategic, transactional and learning motivations. Regardless of the initial motivation, they usually involve some form of knowledge transfer across the collaborators (Griffin 1989; Kale and Singh 2000). Recent empirical research provides some support for the notion that the repeated use of alliances may result in increasing firm capabilities for learning from these mechanisms (Anand and Khanna 2000) ${ }^{1}$. However, in a study of how firms build alliance capabilities, Kale and Singh (2000)

\footnotetext{
${ }^{1}$ It should be noted that alliances may sometimes be used to increase specialization across firms, and therefore not lead to interfirm knowledge building. Mowery, Oxley and Silverman (1996) find that a significant segment of alliances resulted in more divergent technological capabilities.
} 
showed that the internal organizational ability to successfully codify and articulate knowledge is more important than experience in alliance formation. Such work underscores that learning through alliances is not easy. Unlike inter-firm market relationships, alliances require that a firm establish structures and management systems to achieve control over the entity. Further, alliance management is an extensive and tedious process and firms must invest considerable time and management attention to make the relationship successful and achieve a useful transfer of knowledge (Allen 1998).

This recognition of the learning potential and the challenges of alliances has led firms to increasingly focus on setting up organizational mechanisms to properly manage them (Inkpen and Crossan 1995). Thus, if firms treat alliances as extensions of their internal organization, they should accrue the benefits of learning-by-doing and grow increasingly capable at exploiting this learning mechanism. Since senior managers often negotiate alliances, they receive top management attention, and the learning process associated with alliances is less likely to suffer from any negative consequences of size. Thus we suggest that though most firms can learn from alliances, larger firms have superior managerial resources and capabilities to exploit the learning potential of alliances.

H2a: The likelihood of a startup learning from an alliance increases with its size.

\subsubsection{Firm Size and Informal Mechanisms. We suggest here that larger firms} may be less motivated and able to learn from mobility and other geographically mediated mechanisms than their smaller counterparts. As outlined previously, the mobility of experts between firms represents an individual level informal mechanism for learning. Hence, this mechanism is more likely to be subject to the downsides of size, and is likely 
to be ignored as a potential source of inter-firm in larger, more formal organizations. Thus the 'myopia' of learning is likely to be most significant for this informal learning mode.

Mobility of experts has the potential to provide the hiring organization with new skill-sets and also specific knowledge embodied within individuals. Almeida and Kogut (1997) suggest that firms use hiring to fulfill different needs. In larger firms hiring is more likely to be used to fill in skill gaps, while in small firms, targeted knowledge acquisition may be a greater motivation. Unless firms set up specific organizational mechanisms to harness 'learning-by-hiring', they are unlikely to upgrade their capabilities in this area.

$\boldsymbol{H} 2 \boldsymbol{b}$ : The likelihood of a startup learning from hiring an inventor decreases with its size.

Small firms are more likely to be attuned to and reliant on local knowledge networks than larger firms, and are therefore more likely to harness the informal learning channels associated with them. Why should the phenomenon of regional networking benefit smaller firms rather than larger firms? One reason is that larger firms become more self-reliant and fail to build relationships with other institutions within the region. Dynamics of status similarity (Podolny 1993; Chung, Singh et al. 2000) suggest that larger firms, having reached higher-status positions, are likely to look beyond regional constraints for similar-status partners and more cosmopolitan exchange. Also, the paucity of resources in a small firm creates an incentive to rely upon external sources of knowledge. In a rich ethnography of regions in the semiconductor industry, Saxenian (1994) contrasted the industrial systems of the Route 128 region and the Silicon Valley area to explain the comparative success of Silicon Valley. She noted that this region, 
with its greater share of startup firms, is characterized by local collective learning and experimentation, resulting in extensive inter-firm knowledge exchange. In contrast, the Route 128 region is dominated by larger firms that are more insulated from the surrounding institutions. Statistical studies have confirmed the importance of external sourcing of resources by small firms. Feldman (1994) uses Small Business Administration innovation data to ascertain the importance of inputs to innovation for firms of different sizes. She finds that although larger firms benefit from local innovation, for smaller firms the benefits are more significant. The above arguments suggest that larger firms are less able and motivated to learn from informal knowledge mechanisms.

H2c: The likelihood of a startup learning from co-location in a region decreases with its size.

\section{Data \& Methods}

\subsection{Research Setting}

We test our hypotheses in the context of the semiconductor industry. The semiconductor industry is, after all, the apotheosis of a knowledge-based industry and both startups and regions have played a vital parts in the development of the semiconductor industry over the last five decades. The history of the industry is defined by the innovative role of startups. Several of these startups, via successful innovation, grew into large firms, often dominating sections of the industry. Though larger firms now dominate the more established fields (for example the memory and microprocessor segments), new waves of startups continue to bring about technological changes. In the 1980s, small firms dominated innovation in the areas of Application-specific Integrated 
Circuits (ASICs), high performance CMOS memory and logic chips. As ASICs grew more popular over the last decade, many of the startups of the 1980s have grown rapidly. A new wave of startups in the middle 1990s are investigating new and emerging fields such as three-dimensional integrated circuits, voice recognition and synthesis, bioelectronics and optoelectronics.

Another remarkable aspect of the semiconductor industry is the role played by alliances, mobility and regional networks. Kogut and Kim (1992) show that alliances have become increasingly important in the industry - both between firms of different sizes and between firms from different countries. Almeida and Kogut (1999) show that mobility of engineers across firms is an important channel of inter-firm knowledge flows. Finally, technology intensive regions characterize the industry. Numerous descriptive studies have suggested that technology diffusion within regions has been facilitated by the culture of networking and knowledge exchange between engineers (Braun and MacDonald 1982; Saxenian 1991; Rogers 1995).

\subsection{Patent Data}

Since the pioneering work of Schmookler (1966) and Scherer (1984), patent data ${ }^{2}$ have been commonly used by economists to illuminate the process of innovation and to evaluate its relationship to technological and economic development. Patent data have received so much attention because they are systematically compiled, have detailed knowledge and are available continuously across time. We use patent data extensively

\footnotetext{
${ }^{2}$ A patent is the grant of a property right to an inventor for an invention conferred by the government. It establishes the "right to exclude others from making, using or selling the invention" for a period of up to 17 years. A US patent is granted for an invention which is 'useful', 'novel' and 'non-obvious to a person of ordinary skill in the art' (US Department of Commerce, 1992).
} 
and in a variety of ways to shed light on the knowledge building patterns of semiconductor firms.

A patent document contains a host of knowledge including citations to other patents. The list of citations for each patent is arrived at through a uniform and rigorous process applied by the patent examiner as a representative of the patent office. The patent applicant and his or her lawyer are obliged by law to specify in the application any and all of the prior art of which he or she is aware. The list of patent citations so compiled is available on the patent document, along with knowledge on the patenting firm, inventor, geographic location, and technology types. Thus through patent documents, one can infer both organizational and technological influences on a particular innovation and thus track knowledge building across people, firms, geographic regions and countries, and time.

It would be inappropriate to claim that each and every patent citation represents knowledge building, as some citations may be introduced to distinguish the invention from dissimilar ones, or to protect the firm from litigation. While acknowledging this noise in the citation process, we still believe that due to the rigorous and uniform process applied during citation compilation by the patent examiner (unlike the process for academic citations) as well as the widespread use of patenting in the semiconductor industry, patent citations allow us to observe overall tendencies of the interfirm knowledge building process and its location in technological, temporal, and geographic space, which can then be traced to the variety of mechanisms associated with this process. 
In this paper we use the detailed patent knowledge available in a patent document in a number of ways - not only to track interfirm knowledge building through patent citations in the semiconductor industry, but also to track interfirm mobility of semiconductor engineers, to measure technological overlaps between firms in the industry and to locate the innovative activities of these firms in geographic space.

\subsection{Sample Selection}

Research on the history of technological development of the semiconductor industry describes the phenomenon of entry by 'waves' of startups at different points in time (Saxenian 1990). Our sample of startups for this study was drawn from the wave of new firms that entered the industry between 1980 and 1989. Though these startups were located in different regions of the US and abroad, had different years of founding, and focused on different semiconductor technologies, they can together be conceived as a cohort, imprinted by similar underlying technological and industrial conditions prevailing at their founding (Stinchcombe 1965). Given the important role played by this wave of startups in spurring innovation (Dataquest 1990), we follow previous studies (e.g., Kim and Kogut 1996) in examining this set of startup firms to better understand the influences on technological innovation.

We first compiled a list of every semiconductor firm that designed or fabricated semiconductor devices from ICE and Dataquest databases, both private research firms that specialize in semiconductor industry analysis. From this list of firms, we identified 86 firms founded between 1980 and 1989. Fifteen firms were dropped from this set due to missing information on either size ${ }^{3}$, geography, or technology. Our sample thus

\footnotetext{
${ }^{3}$ Eight firms designated as startups by Dataquest or ICE were subunits of larger firms, and size data reflected the larger firm rather than the subunit.
} 
consisted of 71 firms, which we term "startups". Startups had a mean age of 5.86 years, and mean size of about 133 employees.

We defined the potential sources of external learning for each startup to include all other startups as well as all other semiconductor firms founded prior to 1980 . We term these firms founded earlier than 1980 "incumbents". Both incumbents and other startups are important sources of learning for startups. $89 \%$ of the citations made by startups in the study period were to patents filed by incumbents, however incumbents filed over $99 \%$ of semiconductor patents prior to 1990 . The mean age of incumbents was just over 13 years, with a mean size of over 2200 employees ${ }^{4}$. Data was available for 119 incumbents. Thus the unit of analysis we employ is the dyad -- each of the variables of interest is a relationship variable between the receiver of knowledge and the sources of innovative knowledge. ${ }^{5}$

\subsection{Variables}

Descriptive statistics for our data are included in Table 1. We describe each of the variables in turn.

Knowledge building: For each startup, we obtained all semiconductor patents granted between 1990 and 1995. For each patent, we examined each citation to patents filed prior to 1990 and identified the cited firm. Thus, each citation is treated as one instance of the citing firm building upon knowledge of the cited firm. Self-citations were excluded from this set, and citations made to non-semiconductor firms are not included in our sample. A total of 3859 citations (about 54 per firm) were identified. These citations

\footnotetext{
${ }^{4}$ These figures represent only 64 incumbent firms for which age and size information were available. The remaining incumbent firms were primarily subunits of larger firms (e.g. IBM, Fujitsu) for which subunit level data was unavailable.
} 
were concentrated among 1073 dyads. We employed a binary variable to indicate the presence or absence of citations for each dyad.

Mobility: Our aim was to identify as many instances as possible where an inventor moved from one firm in our sample to any of our other firms, thus facilitating interfirm transmission of knowledge from their earlier employer to the new employer. To track mobility, we examined the full set of semiconductor patents for each firm in our sample for the full 1980-1995 period. We then tracked each inventor listed on these patents through the 1980-1995 period, looking for instances where an inventor was employed by more than one firm. For example, if one inventor was listed on patents for Firm A in June 1984, Firm B in April 1986, and Firm C in May 1989, we determined that Firm $\mathrm{C}$ had access to the knowledge of both Firm B and Firm A, while Firm B had access to the knowledge of Firm A. We estimated timing of these moves at the midpoint between the filing dates of the last patent filed at Firm A and the first patent filed at Firm B and we limited the set of instances of mobility to the moves occurring between the beginning 1980 and the end of 1989. 120 instances of mobility were identified between 72 dyads. While this method does not identify every move and does not pinpoint the timing of the move, it provides a picture of the patterns of mobility for engineers and enables us to obtain a conservative estimate of interfirm mobility.

Alliances: We compiled the announcements of every alliance formed among firms in our sample between 1980 and 1989 listed in the weekly publication Electronic

\footnotetext{
5 Thus the total number of dyadic observations is 13419 (71 citing startups multiplied by 190 cited firms less self-cites).
} 
News. ${ }^{6}$ We recorded the complete range of alliances that the firm undertook with other firms in the industry; these types included joint ventures (for design or for fabrication), equity arrangements, and marketing, design, fabrication and licensing agreements. If an alliance was reported as being between three firms, to accommodate our data structure, we coded that alliance as three dyadic alliances, one between each pair of firms. No alliances among groups larger than three were reported for our sample firms. A total of 149 dyadic alliances were identified.

Geographically mediated informal flows: To capture various regional mechanisms that might enable interfirm knowledge flows, we created a binary variable to indicate whether firms were located in the same geographic region. Regions were defined as countries outside of the U.S. and as states within the U.S., with two exceptions. Within the U.S., California was separated into two regions (Northern and Southern California), while four Northeast states (New York, New Jersey, Connecticut, Pennsylvania) were clustered into one region. As such, a total of 63 regions were identified - 48 within the U.S. plus 15 other countries. The regional locations of each firm were obtained from our patent data by consulting its inventors' locations listed on its patents. For each pair of firms, if the inventors were located in the same region, the geographic similarity was set to one; otherwise zero. Because the geographic location was based on inventor location, it was possible for a firm to have multiple locations. We assessed similarity between pairs of firms based on all locations of the inventors in the selected patent set.

\footnotetext{
${ }^{6}$ Electronic News is a weekly publication which extensively covers events in the electronics industry. A detailed search was made of over 520 issues of the publication and every announcement of a semiconductor alliance was listed.
} 
Size: We used the number of employees reported by the startup in 1990 to represent firm size ${ }^{7}$. This variable ranged from a low of 3 to a high of 516. Mean firm size was 133 employees, while the standard deviation was 136 . Due to the skew of this variable, we logged firm size, resulting in a mean value of 4.3 and standard deviation of 1.2.

Controls: Firm age was calculated as the number of years since the firm's founding as of 1990. This variable ranged from 1 to 10 , with a mean of 5.9 and a standard deviation of 2.2 .

Technological similarity captures the extent of technological overlap between pairs of firms. We created a dyadic measure of technological similarity during the 19801989 period. For every firm in our sample, we collected its semiconductor patents between 1980-1989. If the firm had more than ten patents, ten of the set were randomly selected. If the firm had fewer than three patents during this period, we used the earliest possible patent data after 1989. For each patent, we tabulated the technological classes to which the patent was assigned. Aggregating the set of patents for each firm, we summarized the percentage of assignments in each patent class. We then calculated the Euclidean distances between these patent class vectors for each pair of firms. This distance measure theoretically and actually ranged from a low of zero (firms with identical patenting profiles) to a high of 1.4 (the square root of 2; where each firm allocates $100 \%$ of their activity to one class and each firm is active in a different class). Note that with this measure, the higher the distance figure, the less similar the pair of firms.

\footnotetext{
${ }^{7}$ The sources for size and age knowledge were the 1991 CorpTech Corporate Technology Directory and the 1991 Dun's Million Dollar Directory.
} 
Citation Propensities: We also controlled for the number of semiconductor patents the citing firm had in our sample during the 1990-1995 period, which is theoretically associated with a firm's absorptive capacity (i.e., the more knowledge stock, the more knowledge assimilation). It is also associated empirically with the firm's propensity to cite (i.e., the more patents, the more citations). Similarly, we controlled for the number of semiconductor patents the cited firm had received during the 1980-1989 period since that should be empirically associated with the likelihood of the firm receiving citations. Both measures of patent stock were logged.

\subsection{Analyses}

We used logistic regression to examine the determinants of citation within dyads. Model 1 includes our main effects and control variables. Models 2-4 introduce each interaction of mechanisms and size independently, while Model 5 includes all significant interactions.

\section{Results}

The results of the regression analysis are shown in Table 2. Model 1 tests for the relationship between the mechanisms of knowledge transfer and the likelihood of interfirm citation. The table indicates that the likelihood of citation is higher for dyads that have entered into alliances and also for firms that have hired an inventor away from the other member of the dyad. Geographic similarity (or co-location) between the two firms in a dyad likewise increases citation likelihood. As expected technological distance between the firms decreases the likelihood of citation. All these results are significant even after controlling for expected citation propensities derived from patent counts. Thus the initial model supports the findings of Almeida and Rosenkopf (1997) that alliances, 
mobility, as well as technological and geographic similarity simultaneously serve to increase the likelihood of interfirm citation.

Model 1 also tests Hypothesis 1 - namely the relationship between firm size and the likelihood of inter-firm citations. We observe that startup size has a positive effect on the likelihood of it citing other firms, supporting Hypothesis 1. Apparently, the larger the startup, the more likely it is to build upon the knowledge of other firms. Note that this size effect obtains even in the presence of a control for age, which is not significant.

The next four models introduce interaction terms between size and the mechanisms of knowledge flow to test Hypotheses 2a, 2b and 2c. We observe that the interaction of size and the various mechanisms of learning generate negative coefficients. In Model 2 the coefficient of the interaction between alliances and size is insignificant. Thus, counter to Hypothesis 2a, we find no evidence that the likelihood of a startup learning from an alliance varies with firm size. In contrast, Model 3 supports Hypothesis $2 \mathrm{~b}$ - the likelihood of a startup learning from hiring an inventor does indeed decrease with firm size. In addition, Model 4 shows that the interaction between geography and size is negative and significant, thus supporting Hypothesis $2 \mathrm{c}--$ the likelihood of a startup learning from co-location in a region decreases with size. Model 5 includes both significant interaction terms from Models 3 and 4 to demonstrate their all effects simultaneously (pseudo- $\mathrm{R}^{2}=.29$ ). Note that the addition of these interactions improves the fit of Models 3, 4, and 5 over Model 1, as the differences in $-2 * \log$-likelihood are significant $(\mathrm{p}<.05)$.

\section{Discussion}


Our results extend current theory and findings about the role of various mechanisms in facilitating the movement of knowledge between firms. As suggested by previous research, this work replicates findings that alliances, mobility and geographic co-location facilitate interfirm learning. It is our specific focus on startup size and its interaction with the mechanisms of learning that generates a contribution to the technology entrepreneurship literature. Our results suggest a pattern - as startup size increases, learning from other firms increases. Yet our exploration of three identifiable mechanisms of learning suggests the learning effects of mobility and geographic similarity attenuate with size, while learning from alliances is unaffected by startup size. Several issues merit discussion on this front.

First, the relationship between size and learning - a main effect in the presence of controls for our three mechanisms of learning - raises the question of what might lead this result to obtain. Is it simply that startups generate more extensive repertoires of alliance activities as they grow? Or are there other unmeasured mechanisms -organizational activities that facilitate access to, and assimilation of, knowledge? Thus, for example, to what extent do startups increase their interaction with other firms by sending engineers to technical committee meetings, or less formally, by their engineers participating in chat rooms? Future work that can examine such additional mechanisms systematically, and that can explore the extent to which mechanisms serve as complements or substitutes to each other, will be of great value.

Second, and specifically with respect to alliances, we had argued that larger startups are better able to learn from alliances because they have the managerial and organizational resources and capabilities needed to utilize learning from this formal 
mechanism. Our lack of support for this hypothesis may point to the fact that even the larger firms in our sample may not be mature enough to have fully developed the managerial structures and systems to support the learning. ${ }^{8}$ Alternatively, while these structures and systems may indeed be maturing and facilitating learning, perhaps these effects are nonetheless offset by the myopic tendencies we hypothesized would occur for the informal mechanisms.

Third, an interesting feature of our findings is the contrast of the more informal modes of external knowledge sourcing (mobility and geography) against the more formal mode of alliances. We find that while mobility and geographic similarity increase interfirm knowledge flows, these effects decrease with firm size. In contrast, we find that the usefulness of alliance formation does not change with firm size. It appears that the negative effects of size, such as myopia and rigidity, manifest via more informal mechanisms. These results raise the issue that managers may be missing learning opportunities accessible through informal mechanisms such as mobility and geographically mediated social networks. Is this a natural transition for startups as they grow? Or might there be value in managers attending to the retention of these capabilities for harnessing the knowledge from informal channels?

Though our results suggest that the usefulness of informal mechanisms decreases with size, the study does not permit us to distinguish between contrasting reasons for this finding. It is tempting to suggest that decreased citations arising from (say) mobility are an indicator of decreasing capabilities to harness external knowledge. This decrease in capabilities could be because the larger firms look increasingly inward (Sorensen and Stuart 2000) or because informal knowledge flows, rooted in individuals and their 
interactions, are less likely to diffuse through formalized larger organizations. However, the reason for reduced citations may not be an issue of capabilities but of motivation. Smaller firms, for instance, are more likely to hire individuals for their specific technological knowledge and larger firms for broader skill sets (Almeida and Kogut 1997).

Fourth, we note that while age and size are moderately correlated for our observations, we consistently find that size has significant effects of interest, while age does not. These findings suggest that startups are not tied to certain "biological" (or time-based) rhythms with respect to learning; rather, they suggest that any rhythms of learning are tied to the growth of firms. An additional dimension of evolution experience - may also be key here. Our control for startup's recent patents was strongly positive and significant, and this control might be interpreted as an absorptive capacity or experience measure. Future research that can disentangle the effects of these traits is needed.

Several limitations of the study should also be noted. Alliances have been shown to result in firm growth (Powell, Koput et al. 1996). More generally, while firm size enhances learning, such learning, via any mechanism, may subsequently promote further growth. In the present study, our cross-sectional data structure prevented us from evaluating this positive feedback loop. Future research must move toward longitudinal data structures that would allow researchers to untangle these endogeneities.

The generalizability of our study may be limited by our choice to focus on a particular cohort of startups. Prior or subsequent waves of startups may not experience these same effects. Indeed, the recent attention given to development of "alliance 
capability" (Anand and Khanna 2000) and to the "swat-like precision" with which Cypress Semiconductor conducts recruiting raids for engineers (O'Reilly 1998) suggests that managers may now be induced to devote more attention to generating and harnessing capabilities for learning through experience for many mechanisms.

In addition, our decision to examine a ten-year-long cohort of startups may have unintended consequences. On one hand, we tested the robustness of our results by restricting our analyses to smaller sets of younger firms (e.g., firms 5 years or younger rather than 10 years or younger) and found that all effects were comparable save that of alliances and the interaction of size and geographic similarity, which both became insignificant. Alliances may not manifest as an effective learning mechanism for very young firms simply because alliances may require a longer time to result in learning, because of their formality and structure. Alliances commonly involve multiple people and a delimited set of information to be transferred, making the task of learning more complex than say, mobility. The insignificance of the interaction between size and geographic similarity suggests that while the effects of mobility for external learning are particularly critical in the earliest stages of startups, the effects of geographic proximity endure somewhat longer. On the other hand, one might argue that a more thorough examination of external learning could examine incumbents simultaneously to explore whether these size effects persist in cohorts that have existed longer, and in which firms may have grown correspondingly bigger.

\section{Conclusion}


The field of technological entrepreneurship centers on the study of the exploitation of opportunities. We find here that the technological opportunities made available through the mechanisms of external learning are not utilized equally by all firms. The study highlights one firm characteristic - size -- that may explain differential access to external knowledge opportunities. Increased size may enhance a firm's potential and abilities to exploit opportunities but this may be offset by decreased motivation to utilize informal mechanisms of learning. The findings of our study offer a glimpse into the unique role of startups in informal knowledge networks and suggest reasons why some of the smallest firms play a prominent role in industries characterized by a high degree of technological opportunity. 


\section{REFERENCES}

1. Acs, Z. J. and D. B. Audretsch (1990). Innovation and small firms. Cambridge, MA, MIT Press.

2. Ahuja, G. and C. M. Lampert (2000). Entrepreneurship in the large corporation: a longitudinal study of how established firms create breakthrough inventions. Working Paper.

3. Allen, J. W. (1998). "Capital Markets and Corporate Structure: The Equity CarveOuts of Thermo Electron.” Journal of Financial Economics 48(1): 99-124.

4. Allen, R. C. (1983). “Collective Invention.” Journal of Economic Behavior \& Organization 4(1): 1-24.

5. Almeida, P., R. Grant, et al. (1998). The role of the international corporation in cross border knowledge transfer. Managing strategically in an interconnected world. M. A. Hitt, J. E. R. i. Costa and R. D. Nixon. Chichester, England ; New York, John Wiley.

6. Almeida, P. and B. Kogut (1997). “The Exploration of Technological Diversity and the Geographic Localization of Innovation.” Small Business Economics 9(1): 21-31.

7. Almeida, P. and B. Kogut (1999). "Localization of knowledge and the mobility of engineers in regional networks.” Management Science 45(7): 905-917.

8. Almeida, P. and L. Rosenkopf (1997). Interfirm Knowledge Building by Semiconductor Startups: The Role of Alliances and Mobility. Working Paper.

9. Anand, B. N. and T. Khanna (2000). "Do firms learn to create value? The case of alliances." Strategic Management Journal 21(3; Special Issue: Strategic Networks): 295-315.

10. Bartlett, C. A. and S. Ghoshal (1989). Managing across borders: the transnational solution. Boston, MA, Harvard Business School Press.

11. Bell, M. (1984). Learning and the accumulation of industrial technological capacity in developing countries. Technological Capability in the Third World. M. Fransman and K. King. New York, St. Martin's Press: 187-209.

12. Boeker, W. (1997). "Executive migration and strategic change: The effect of top manager movement on product-market entry." Administrative Science Quarterly 42(2): 213-236 24 pages.

13. Braun, E. and S. MacDonald (1982). Revolution in miniature : the history and impact of semiconductor electronics. New York, Cambridge University Press.

14. Chung, S., H. Singh, et al. (2000). Complementarity, status similarity and social capital as drivers of alliance formation. Strategic Management Journal. 21: 1-22.

15. Cohen, W. M. and D. A. Levinthal (1990). “Absorptive Capacity: A New Perspective on Learning and Innovation.” Administrative Science Quarterly 35(1): 128-152.

16. Dataquest (1990). A decade of semiconductor start-ups. San Jose, CA.

17. Dorfman, N. S. (1987). Innovation and market structure: lessons from the computer and semiconductor industries. Cambridge, MA, Ballinger. 
18. Doz, Y. L. (1996). “The evolution of cooperation in strategic alliances: Initial conditions or learning processes?" Strategic Management Journal 17(Evolutionary Perspectives on Strategy): 5524 pages.

19. Dyer, J. H. and K. Nobeoka (2000). "Creating and managing a high-performance knowledge-sharing network: The Toyota case.” Strategic Management Journal 21(3; Special Issue: Strategic Networks): 345-367.

20. Eisenhardt, K. M. and C. B. Schoonhoven (1996). "Resource-based view of strategic alliance formation: Strategic and social effects in entrepreneurial firms." Organization Science 7(2): 136-150.

21. Feldman, M. P. (1994). "Knowledge Complementarity and Innovation.” Small Business Economics 6(5): 363-72.

22. Griffin, A. J. (1989). "Semiconductor Technology Flow Through Formal Transfer Mechanisms.” IEEE Transactions on Engineering Management 36(2): 148.

23. Gulati, R. (1995). "Social structure and alliance formation patterns: A longitudinal analysis." Administrative Science Quarterly 40(4): 619-652.

24. Hamel, G., Y. L. Doz, et al. (1989). Collaborate with Your Competitors -- and Win. Harvard Business Review. 67: 133.

25. Hayek, F. A. (1945). "The use of knowledge in society." American Economic Review 35(4): 519-530.

26. Herrigel, G. (1993). Large firms, small firms, and the governance of flexible specialization: The case of Baden-Wurttemberg and socialized risk. Country Competitiveness. B. Kogut. New York, Oxford University Press.

27. Inkpen, A. C. and M. M. Crossan (1995). "Believing is seeing: Joint ventures and organization learning." The Journal of Management Studies 32(5): 59524 pages.

28. Jewkes, J., D. Sawers, et al. (1958). The sources of invention. London, Macmillan.

29. Kale, P. and H. Singh (2000). Alliance Capability and Success: A Knowledge Based Approach. Working Paper.

30. Katz, R. and T. J. Allen (1982). "Investigating the Not Invented Here (NIH) Syndrome: A Look at the Performance, Tenure and Communication Patterns of 50 R\&D Project Groups.” R\&D Management 12(1): 7-19.

31. Kim, D.-J. and B. Kogut (1996). “Technological platforms and diversification.” Organization Science 7(3): 283-301.

32. Kogut, B. and D.-J. Kim (1992). Strategic Alliances in the Semiconductor Industry. Philadelphia, Wharton School, University of Pennsylvania.

33. Kogut, B. and U. Zander (1993). "Knowledge of the firm and the evolutionary theory of the multinational enterprise." Journal of International Business Studies 24(4): 625.

34. Levinthal, D. A. and J. G. March (1993). The myopia of learning. Philadelphia, Wharton School of the University of Pennsylvania, Snider Entrepreneurial Center. 
35. Liebeskind, J. P., A. L. Oliver, et al. (1996). "Social networks, learning, and flexibility: Sourcing scientific knowledge in new biotechnology firms." Organization Science 7(4): 428-443.

36. Malecki, E. J. (1991). Technology and economic development : the dynamics of local, regional, and national change. New York, Wiley.

37. March, J. G. (1991). "Exploration and exploitation in organizational learning." Organization Science 2(1): 71-87.

38. Markusen, A. R., P. Hall, et al. (1986). High tech America : the what, how, where, and why of the sunrise industries. Boston, Allen \& Unwin.

39. Mowery, D. C., J. E. Oxley, et al. (1996). "Strategic Alliances and Interfirm Knowledge Transfer.” Strategic Management Journal 17(Winter Special Issue): 7791.

40. O'Reilly, C. (1998). Cypress Semiconductor (A): Vision, Values, and Killer Software. Case Study, April. Stanford Graduate School of Business.

41. Patel, P. and L. Soete (1987). Technological Trends and Employment in the UK Manufacturing Sectors. Technical change and full employment. C. Freeman and L. Soete. Oxford and New York, Blackwell: p 122-168.

42. Piore, M. J. and C. F. Sabel (1984). The second industrial divide: possibilities for prosperity. New York, Basic Books.

43. Podolny, J. M. (1993). “A Status-Based Model of Market Competition.” American Journal of Sociology 98(4): 829-872.

44. Porter, M. E. (1990). The competitive advantage of nations. New York, Free Press.

45. Powell, W. W., K. W. Koput, et al. (1996). "Interorganizational collaboration and the locus of innovation: Networks of learning in biotechnology." Administrative Science Quarterly 41(1): 116-145.

46. Rogers, E. M. (1995). The diffusion of innovations. New York, Free Press.

47. Rogers, E. M. and J. K. Larson (1984). Silicon Valley fever: growth of hightechnology culture. New York, Basic Books.

48. Rosenkopf, L., A. Metiu, et al. (2000). Strategic Participation in Industry-Wide Communities? Voluntary Technical Associations as Context for Alliance Formation. Working Paper.

49. Rosenkopf, L. and A. Nerkar (forthcoming). On the complexity of technological evolution: Exploring coevolution within and across hierarchical levels in optical disk technology. Variations in Organization Science: In Honor of D. T. Campbell. J. Baum and W. McKelvey, Sage Publications: 169-183.

50. Rosenkopf, L. and M. L. Tushman (1998). "The Coevolution of Community Networks and Technology: Lessons from the Flight Simulation Industry." Industrial \& Corporate Change 7(2): 311-46.

51. Sakakibara, K. and D. E. Westney (1992). Japan's Management of Global Innovation: Technology Management Crossing Borders. Technology and the wealth of nations. 
N. Rosenberg, R. Landau and D. C. Mowery. Stanford, Stanford University Press: p 327-43.

52. Saxenian, A. (1990). Regional Networks and the Resurgence of Silicon Valley. California Management Review. 33: 8924 pages.

53. Saxenian, A. (1991). "The Origins and Dynamics of Production Networks in Silicon Valley." Research Policy 20(5): 423.

54. Saxenian, A. (1994). Regional advantage : culture and competition in Silicon Valley and Route 128. Cambridge, MA, Harvard University Press.

55. Scherer, F. M. (1984). Innovation and growth : Schumpeterian perspectives. Cambridge, MA, MIT Press.

56. Schmookler, J. (1966). Invention and economic growth Cambridge, MA, Harvard University Press.

57. Shane, S. and S. Venkataraman (2000). "The promise of entrepreneurship as a field of research." Academy of Management Review 25(1): 217-226.

58. Sorensen, J. B. and T. E. Stuart (2000). Aging, obsolescence and organizational innovation. forthcoming.

59. Stinchcombe, A. (1965). Social structure and organizations. Handbook of Organizations. J. G. March. Chicago, Rand McNally.

60. Stuart, T. E. (1998). "Network positions and propensities to collaborate: An investigation of strategic alliance formation in a high-technology industry." Administrative Science Quarterly 43(3): 668-698.

61. Stuart, T. E. and J. M. Podolny (1996). "Local search and the evolution of technological capabilities." Strategic Management Journal 17(Evolutionary Perspectives on Strategy Supplement)): 21-38.

62. Venkataraman, S. (1997). "The distinctive domain of entrepreneurship research." Advances in Entrepreneurship, Firm Emergence and Growth 3: 119-138.

63. von Hippel, E. (1994). ""Sticky information" and the locus of problem solving: Implications for innovation." Management Science 40(4): 429.

64. Zucker, L. G. (1998). "Geographically Localized Knowledge: Spillovers or Markets?” Economic Inquiry 36(1): 65-86. 
Table 1: Descriptive Statistics

\begin{tabular}{|c|c|c|c|c|c|c|c|c|c|c|c|c|}
\hline & Mean & $\mathrm{SD}$ & Min & Max & 2 & 3 & 4 & 5 & 6 & 7 & 8 & 9 \\
\hline (1) Alliance & .01 & .10 & 0 & 1 & .06 & .04 & .05 & -.04 & .05 & .02 & .06 & .07 \\
\hline (2) Mobility & .01 & .15 & 0 & 1 & -- & .05 & .03 & -.05 & .01 & .05 & .07 & .14 \\
\hline $\begin{array}{l}\text { (3) Geographic } \\
\text { Similarity }\end{array}$ & .32 & .47 & 0 & 1 & -- & -- & .03 & -.01 & .02 & .002 & -.02 & .06 \\
\hline (6) Age & 5.86 & 2.24 & 1 & 10 & -- & -- & -- & -- & -- & .02 & -.001 & .01 \\
\hline $\begin{array}{l}\text { (7) Log (Citer } \\
\text { Patents) }\end{array}$ & 1.97 & 1.00 & 0 & 4.13 & -- & -- & -- & -- & -- & -- & -.001 & .23 \\
\hline
\end{tabular}


Table 2

Logistic Regression Coefficients for Citation of Firm j by Firm i

(Standard Errors in Parentheses)

\begin{tabular}{|c|c|c|c|c|c|}
\hline & 1 & 2 & 3 & 4 & 5 \\
\hline Alliance & $\begin{array}{l}.64 * * * \\
(.24)\end{array}$ & $\begin{array}{c}.98 \\
(1.30)\end{array}$ & $\begin{array}{l}.65 * * * \\
(.24)\end{array}$ & $\begin{array}{c}.65^{* * * *} \\
(.24)\end{array}$ & $\begin{array}{c}.66^{* * * *} \\
(.24)\end{array}$ \\
\hline $\begin{array}{l}\text { Mobility from } \mathrm{j} \\
\text { to } \mathrm{i}\end{array}$ & $\begin{array}{c}1.28 * * * \\
(.25)\end{array}$ & $\begin{array}{c}1.28 * * * \\
(.24)\end{array}$ & $\begin{array}{c}4.40 * * * \\
(1.37)\end{array}$ & $\begin{array}{c}1.29 * * * \\
(.25)\end{array}$ & $\begin{array}{c}4.29 * * * \\
(1.37)\end{array}$ \\
\hline Geographic & $.66 * * *$ & $.66^{* * *}$ & $.65 * * *$ & $1.27 * * *$ & $1.24 * * *$ \\
\hline Similarity & $(.08)$ & $(.08)$ & $(.08)$ & $(.31)$ & $(.31)$ \\
\hline Log (Size) & $\begin{array}{l}.10 * * * \\
(.04)\end{array}$ & $\begin{array}{l}.10 * * * \\
(.04)\end{array}$ & $\begin{array}{c}.11 * * * \\
(.04)\end{array}$ & $\begin{array}{l}.14 * * * \\
(.04)\end{array}$ & $\begin{array}{c}.15^{* * * *} \\
(.04)\end{array}$ \\
\hline $\begin{array}{l}\log (\text { Size }) x \\
\text { Alliance }\end{array}$ & & $\begin{array}{l}-.07 \\
(.27)\end{array}$ & & & \\
\hline $\begin{array}{l}\log (\text { Size }) x \\
\text { Mobility }\end{array}$ & & & $\begin{array}{c}-.64 * * \\
(.27)\end{array}$ & & $\begin{array}{c}-.62 * * \\
(.27)\end{array}$ \\
\hline $\begin{array}{l}\text { Log (Size) x } \\
\text { Geography }\end{array}$ & & & & $\begin{array}{c}-.14 * * \\
(.07)\end{array}$ & $\begin{array}{l}-.13^{*} \\
(.07)\end{array}$ \\
\hline $\begin{array}{l}\text { Technological } \\
\text { Similarity }\end{array}$ & $\begin{array}{c}-1.71 * * * \\
(.18)\end{array}$ & $\begin{array}{c}-1.71 * * * \\
(.18)\end{array}$ & $\begin{array}{c}-1.71 * * * \\
(.18)\end{array}$ & $\begin{array}{c}-1.74 * * * \\
(.18)\end{array}$ & $\begin{array}{c}-1.74 * * * \\
(.18)\end{array}$ \\
\hline Age & $\begin{array}{l}-.03 \\
(.02)\end{array}$ & $\begin{array}{l}-.03 \\
(.02)\end{array}$ & $\begin{array}{l}-.03 \\
(.02)\end{array}$ & $\begin{array}{l}-.03 \\
(.02)\end{array}$ & $\begin{array}{l}-.03 \\
(.02)\end{array}$ \\
\hline $\begin{array}{l}\text { Log (Citer } \\
\text { Patents) }\end{array}$ & $\begin{array}{l}.88 * * * \\
(.04)\end{array}$ & $\begin{array}{c}.88 * * * \\
(.04)\end{array}$ & $\begin{array}{c}.88 * * * \\
(.04)\end{array}$ & $\begin{array}{l}.88 * * * \\
(.04)\end{array}$ & $\begin{array}{c}.88^{* * * *} \\
(.04)\end{array}$ \\
\hline Log (Citee & $.39 * * *$ & $.39 * * *$ & $.39 * * *$ & $.39 * * *$ & $.39 * * *$ \\
\hline Patents) & $(.01)$ & $(.01)$ & $(.01)$ & $(.01)$ & $(.01)$ \\
\hline Intercept & $\begin{array}{c}-5.69 * * * \\
(.23)\end{array}$ & $\begin{array}{c}-5.69 * * * \\
(.23)\end{array}$ & $\begin{array}{c}-5.71 * * * \\
(.23)\end{array}$ & $\begin{array}{c}-5.87 * * * \\
(.25)\end{array}$ & $\begin{array}{c}-5.89 * * * \\
(.26)\end{array}$ \\
\hline Log-likelihood & -2669.51 & -2669.47 & -2666.68 & -2667.50 & -2664.86 \\
\hline $\mathrm{N}$ & 13419 & 13419 & 13419 & 13419 & 13419 \\
\hline
\end{tabular}

$* \mathrm{p}<.10 ; * * \mathrm{p}<.05 ; * * * \mathrm{p}<.01$ 